\title{
Parenting Styles and Self-Efficacy among Secondary School Students in Ibanda North, Ibanda District, Uganda
}

\author{
${\text { Japheth } \text { Noel }^{1} \& \text { Imelda Kemeza }}^{2} \&$ Esther Njeri Kiaritha $^{3} \&$ Davis Muhwezi $^{4}$
}

\author{
${ }^{1,2 \& 4}$ Department of Educational Foundations and Psychology, Mbarara University of Science and \\ Technology, Mbarara, Uganda \\ ${ }^{3}$ Department of Educational Psychology, Moi University, Eldoret, Kenya \\ Correspondence: Japheth Noel, Mbarara University of Science and Technology, Mbarara, Uganda. \\ Email: 2018med010@std.must.ac.ug
}

Doi: $10.23918 /$ ijsses.v8i2p135

\begin{abstract}
The main purpose of the current study was to analyze the relationship between parenting styles and self-efficacy among secondary school students in Ibanda North, Ibanda district Uganda. The study also examined the contribution of individual parenting styles in predicting students' self-efficacy. The study was quantitative and cross sectional-correlational in nature. Questionnaires were used to gather data from 290 participants $136(47 \%)$ males and 154(53\%) females. Data were analyzed using Statistical Package for the Social Sciences (SPSS) version 21.0. The findings of the study showed that there was moderate positive significant correlation between authoritative parenting style and self-efficacy $(r=.365, p<0.01)$. Authoritarian parenting style had a low positive significant relationship with self-efficacy $(r=.169, p<0.01)$. Permissive parenting style had a low positive insignificant relationship with self-efficacy $(r=.090, p>0.01)$ and uninvolved parenting style had a low negative relationship with self-efficacy $(r=. .090, p>0.01)$. All parenting styles computed together indicated a high positive significant relationship with self-efficacy $(r=.620, p>0.01)$. On individual parenting styles' contribution to predicting self-efficacy, findings revealed that only authoritative parenting style was significant $t(285)=5.673, p(.000)<.05$. The study, therefore, recommends that parents should adopt authoritative and authoritarian parenting styles, teachers should give necessary support to students taking in mind the parenting setting they could be coming from, schools should take an initiation of encouraging parents do adopt positive parenting styles.
\end{abstract}

Keywords: Authoritative, Authoritarian, Permissive, Uninvolved Parenting Styles, Self-Efficacy

\section{Introduction}

Pioneering efforts of Baurmrind gave parenting researchers a major shift from focusing on parenting dimensions (only characteristics) to three major parenting styles in 1960s. These parenting styles included authoritative, authoritarian and permissive parenting styles (Power, 2015). Later on, in the third study, Baumrind confirmed the fourth parenting style which she termed as neglectful parenting style (Baumrind

Received: May 11, 2021

Accepted: June 21, 2021

Noel, J., \& Kemeza' I., Kiaritha, E.N., \& Muhwezi, D. (2021). Parenting Styles and Self-Efficacy among Secondary School Students in Ibanda North, Ibanda District, Uganda. International Journal of Social Sciences \& Educational Studies, 8(2), 135-148. 
\& Black, 1967). This was later described by Maccoby and Martin (1983) as a parenting style with low responsiveness and demandingness and named it as uninvolved style. Our current study focused on the above four parenting style to establish how they are related to students' self-efficacy in Ibanda district and how each individual parenting style contribute to predicting self-efficacy.

Students' perceptions of their capabilities to accomplish their learning goals cannot be underrated in enhancing their wellbeing. The capacity to judge one's capabilities is definitely an aspect of self-efficacy (Bandura, 2010). Self-efficacy is realized from a person's self-esteem, persistence level, and personal behaviors (Qamar et al., 2017). Personal beliefs, emotions, feelings, thoughts and general wellbeing are managed by ones self-efficacy (Bandura as cited in Cahyadi \& Padjadjaran, 2018). Several studies indicate that the level of students' self-efficacy differs from one student to another (Oyugi, 2015; Shkullaku, 2013; Masud et al., 2016; Meera \& Jumana, 2015; Hayat et al., 2020; Cornelius-Ukpepi \& Ndifon, 2015; Kemeza et al., 2020). Self-efficacy attributed to several factors including parenting styles (Qamar et al., 2017).

Students' self-belief, confidence, and motivation in accomplishing tasks are developed largely by the family parents in line with their particular parenting styles (Masud et al., 2016). According to Harter (2011), competences and beliefs (efficacy) in children are effectively imparted in children by the parents. This is also supported by Eccles et al. (1997). Parenting styles are significantly related to the self-efficacy of adolescent students because they can either develop a positive or negative self-image, self-esteem, and self-confidence (Lord et al., 1994). This depends on the parenting style a parent possess, for instance, previous studies found that adolescents who perceive their parents to be authoritative have higher values and beliefs of self-efficacy, while self-efficacy beliefs are lowest in adolescents who perceive their parents to be non-authoritative (Alsheikh, 2015), this is also noted in (Masud et al., 2016). Therefore, this indicates a clear relationship between parenting styles and self-efficacy hence provoked the need for a study of this kind to establish how each affects the other among secondary school students in Ibanda North Ibanda District.

According to Tam et al. (2012), children who experience permissive parenting techniques express low self-esteem, low persistence to learning, a high level of frustration, delinquent behaviors, poor academic competences, and low levels of psychological functioning. The same study shows that children who explained their parents as authoritarians had low self-esteem as well as low academic achievement. On the other hand, authoritative ones expressed high levels of self-esteem as well as academic achievement. The study, therefore, explored how self-efficacy could be well modified in students' lives to enhance positive self-esteem in them. It further intended to investigate how parenting styles related to self-efficacy among secondary school students in Ibanda North, Ibanda district, Uganda.

Guided by Baumrind (1971) typology for parenting styles as cited in (Kuppens \& Ceulemans, 2019), we considered four parenting styles (Authoritative, Authoritarian, Permissive and uninvolved). Our purpose was to test the relationship between each parenting style and students' self-efficacy and the contribution of each parenting style in predicting self-efficacy among secondary schools in Ibanda District. 


\section{Methods}

\subsection{Procedure and Participants}

Approval for the study was obtained from the Mbarara University of Science and Technology Research Ethics Committee after which we thought permission from Head Teachers of selected schools to conduct the study. Head teachers introduced us to schools and gave us opportunity to share more about the study.

We arranged meetings with class teachers and shared information about the study, after which students class lists were obtained. The lists were used as sampling frames to select the participants in each school. All selected participants were briefed on the purpose of the study, the meaning of the study variables, the researchers' expectations, and the ethical considerations such as the anonymity of the participants. Both consent and assent was sought from particular participants.

The participants were oriented on how to fill the questionnaires before they were given to them. On completion of filling the questionnaire, the researchers with the participants crosschecked to ensure all questions were responded to. Researchers collected questionnaires from the participants immediately at the end of every session, counted them and sealed them in envelops.

A total of 290 students sampled from the target population of 1200 students participated in the study. The above sample was drawn from three government aided secondary schools in Ibanda North, Ibanda District. To come up with the above sample, we used Kothari (2004) sample size determination formula (see below) and thereafter, 291 participants were selected using simple random sampling. Only one participant turned down the request to participate in the study hence a response rate of $99 \%$ which was considered sufficient to continue the study (Kothari, 2004).

$$
n=\frac{z^{2} \cdot p \cdot q \cdot N}{e^{2}(N-1)+z^{2} \cdot p \cdot q}
$$

Where

$(\mathrm{N})=$ Target population

$(\mathrm{z})=\mathrm{Z}$-score at confidence level $95 \%$ is 1.96

(e) $=$ Margin of error $5 \%$

$(\mathrm{p})=$ Population portion assumed to be $50 \%(0.5)$

$(\mathrm{q})=1-\mathrm{p}$ is 0.5

\subsection{Measures}

We used standardized questionnaires to generate data. The questionnaire was preferred because the study set to solicit effective responses, and collect both subjective and objective data from a sample of 290 participants and the study population to obtain statistically significant results, especially when resources are limited. Responses on parenting styles were obtained using the parental authority questionnaire (Raval, 
2013) and parenting style four-factor questionnaire (Shyny, 2017). We used a 10 item general self-efficacy five point Likert scale (not at all true, hardly true, not sure, moderately true, and exactly true) (Schwarzer \& Jerusale, 1995) to collect data on self-efficacy from students.

\subsection{Analysis}

We used correlational analysis to test the relationship between parenting styles and self-efficacy and a regression analysis to establish the contribution of each parenting style in predicting self-efficacy using the data obtained from students. To ensure reliable results from regression and correlational analyses, a test for the assumptions of normal distribution of data, independence of the error terms and multicollinearity with in variables was conducted.

\subsection{Tests of Normality}

To ensure that data on parenting styles and self-efficacy variables was normally distributed, normality tests were conducted. This was done through obtaining Kurtosis and Skewness statistic values with the help of SPSS 21.0 version. Skewness concerns the symmetrical shape of data and kurtosis displays the peakedness of the data shape (Mishra et al., 2019). Normality tests were done because it was not clear whether the collected data had a normal distribution. Results are presented in the Table 1 below.

Table 1: Descriptive statistics of normality tests

\begin{tabular}{|l|l|l|l|l|l|l|l|}
\hline & $\mathrm{N}$ & Mean & \multicolumn{2}{l|}{$\begin{array}{l}\text { Std. } \\
\text { Deviation }\end{array}$} & \multicolumn{2}{l|}{ Skewness } & \multicolumn{2}{l|}{ Kurtosis } \\
\cline { 2 - 9 } & Statistic & Statistic & Statistic & Statistic & $\begin{array}{l}\text { Std. } \\
\text { Error }\end{array}$ & Statistic & $\begin{array}{l}\text { Std. } \\
\text { Error }\end{array}$ \\
\hline Authoritative & 290 & 3.5062 & .70468 & -.473 & .143 & .217 & .285 \\
\hline Authoritarian & 290 & 3.2631 & .69206 & -.497 & .143 & .672 & .285 \\
\hline Permissive & 290 & 2.5643 & .62243 & .009 & .143 & -.044 & .285 \\
\hline Uninvolved & 290 & 2.3479 & .74968 & .508 & .143 & .015 & .285 \\
\hline Self-efficacy & 290 & 3.4655 & .76125 & .024 & .143 & -.514 & .285 \\
\hline Valid N (listwise) & 290 & & & & & & \\
\hline
\end{tabular}

Source: Survey Data 2020

The results as presented in the Table 1 above indicated that skewness statistic and kurtosis statistic values were in the range .609- - .497 and $.672--.514$ respectively. According to Mishra et al. (2019), the requisite range for normally distributed data is between -1 and +1 mostly in moderate sample size of about 300 respondents. All the statistic values of skewness and kurtosis for parenting styles and self-efficacy were in the range -1.00 and +1.00 hence the distribution of data for the variables was normal.

\subsection{Test of Independence of the Error Terms}

According to Li et al. (2020), when running the regression one of the assumptions is that residues of data should be independent of one another. This was determined by testing the independence of error terms in 
the current study. Durbin-Watson test was used to determine the test of independence of the error terms among the data obtained on parenting styles and self-efficacy. Results are indicated in table 2 below.

Table 2: Model summary

\begin{tabular}{|l|l|l|l|l|l|}
\hline \multicolumn{4}{|l|}{ Model Summary } \\
\hline Model & $\mathrm{R}$ & R Square & $\begin{array}{l}\text { Adjusted } \\
\text { R Square }\end{array}$ & $\begin{array}{l}\text { Std. Error of } \\
\text { the Estimate }\end{array}$ & Durbin-Watson \\
\hline 1 & $.316^{\mathrm{a}}$ & .100 & .084 & .71514 & 2.020 \\
\hline
\end{tabular}

Durbin-Watson test was used to test for the presence of serial correlation among the residuals. The value of Durbin-Watson test statistic ranges from 0 to 4 as suggested (Huber \& Melly, 2015), the residuals are not correlated if the Durbin-Watson statistic is approximately 2 and the acceptable range is $1.5-2.50$. The Durbin-Watson statistic for the model was 2.020. Thus, there was independence of the error terms.

\subsection{Multi-collinearity Tests}

To guard against the redundancy of data among parenting styles and self-efficacy independent variables during regression analysis in the study, we conducted a multi-collinearity test. This was done on basis of multiple linear regression basic assumption that explanatory variables should be independent of one another (Senaviratna \& Cooray, 2019; Field, 2009; Joshi, 2012). Multi-collinearity is a situation where by two or more of the independent/explanatory variables in the study are highly correlated in a regression (Senaviratna \& Cooray, 2019; Creswell 2018). This indicates that there is redundancy in the data being used to run the regression analysis which causes challenges in the interpretation of the regression results.

Researchers were sensitive on multi-collinearity because the study employed questionnaire data collection method and data was being collected from the same category of participants. More so, there were identities in definitions of parenting styles and self-efficacy items. Guided by Ullah et al. (2019), researchers learned that collinearity may occur due to a number of reasons including but not limited to method of data collection, model and population constraints and existence of identities or definitional relationship, hence moved on to asses it.

Multi-collinearity can be assessed using several tests for instance, correlational analysis, Value of tolerance, Variance Inflation Factor (VIF) and Condition Index. In the current study, collinearity was assessed using Variance Inflation Factors (VIF). This was done through running a linear regression analysis in SPSS at a confidence level of $95 \%$ by checking in collinearity diagnostics. 'A threshold of Variance inflation factor of not more than 10 and a tolerance value of between 0.2 and 10 ' indicates that multicollinearity is not expected (Field, 2009 as noted in Njage, 2020). Results are as presented in Table 3 below. 
Table 3: Coefficients

\begin{tabular}{|l|l|l|l|}
\hline \multicolumn{2}{|l|}{ Coefficients $^{\mathrm{a}}$} & Collinearity Statistics \\
\cline { 3 - 4 } \multicolumn{2}{|l|}{ Model } & Tolerance & VIF \\
\hline \multirow{3}{*}{1} & Authoritative & .746 & 1.340 \\
\cline { 2 - 4 } & Authoritarian & .874 & 1.145 \\
\cline { 2 - 4 } & Permissive & .919 & 1.088 \\
\cline { 2 - 4 } & Uninvolved & .870 & 1.150 \\
\cline { 2 - 4 } & Self-efficacy & .858 & 1.166 \\
\hline \multicolumn{2}{|l|}{ a. Dependent Variable: Self-efficacy } \\
\hline
\end{tabular}

Source: Survey Data 2020

The variance inflation factor values for parenting styles were in the range of 1.088 to 1.340 on the other hand, the variance inflation factor of Self-efficacy was 1.166. All independent variables had the variance inflation factor values less than 10 therefore collinearity was not expected

\section{Results}

A Pearson's correlation tested the relationship that existed between parenting styles and self-efficacy among secondary school students in Ibanda North, Ibanda district. The test was done because computed data was normally distributed and no collinearity was expected. The study further established linear relationships between individual parenting styles and self-efficacy among students. The results are presented in Table 4 below.

Table 4: Parenting styles and self-efficacy academic performance correlation coefficients

\begin{tabular}{|l|l|l|l|l|l|l|}
\hline & & 1 & 2 & 3 & 4 & 5 \\
\hline 1 & Self-efficacy & 1 & & & & \\
\hline 2 & Authoritative & $.365^{* *}$ & 1 & & & \\
\hline 3 & Authoritarian & $.169^{* *}$ & $.351^{* *}$ & 1 & & \\
\hline 4 & Permissive & .088 & .016 & .009 & 1 & \\
\hline 5 & Uninvolved & -.090 & $-.244^{* *}$ & $-.189^{* *}$ & $.258^{* *}$ & 1 \\
\hline
\end{tabular}

Source: Survey data 2020. 
Table 5: Overall parenting styles and self-efficacy correlation coefficients

\begin{tabular}{|l|l|l|l|}
\hline \multicolumn{2}{|c|}{} & Parenting Styles & Self-efficacy \\
\hline PS & Pearson Correlation & 1 & $.620^{* *}$ \\
\cline { 2 - 4 } & Sig. (2-tailed) & & .000 \\
\cline { 2 - 4 } & $\mathrm{N}$ & 290 & 290 \\
\hline \multirow{4}{*}{ As } & Pearson Correlation & $.620^{* *}$ & 1 \\
\cline { 2 - 4 } & & & \\
\cline { 2 - 4 } & Sig. (2-tailed) & .000 & 290 \\
\cline { 2 - 4 } & $\mathrm{N}$ & 290 & \\
\hline$* *$. Correlation is significant at the 0.01 level (2-tailed). \\
\hline
\end{tabular}

Findings as presented in the Table 4 above indicated that authoritative and authoritarian parenting styles were associated to students' self-efficacy at a level of 0.01 , uninvolved parenting style was associated to students' self-efficacy at a level of 0.01 . Hence the relationships were significant. Authoritative parenting style and self-efficacy had a positive significant relationship $(\mathrm{r}=.365, \mathrm{p}<0.01)$. Authoritarian parenting style and self-efficacy had a positive significant relationship $(\mathrm{r}=.169, \mathrm{p}<0.01)$. Uninvolved parenting style and self-efficacy had a negative relationship which was not significant $(\mathrm{r}=-.090, \mathrm{P}>0.01)$. Permissive parenting style had no statistical significant relationship with self-efficacy $(r=088, p>0.01)$. We further computed all parenting styles as one variable and correlated it to self-efficacy. In table 5 above, it is indicated that the overall parenting styles had a positive statistical significant relationship with students' self-efficacy $(\mathrm{r}=.620, \mathrm{p}>0.01)$.

To examine the contribution of individual parenting styles on predicting self-efficacy among secondary school students in Ibanda North, we run a multiple linear regression. Multiple linear regression tests were used because collinearity was not expected within data. Multicollinearity test and test of independence of error terms were conducted first. Results revealed that all independent variables had the variance inflation factor values less than 10 and the Durbin-Watson statistic for the model was 2.020. Findings are presented in the Table 6, 7 and 8 below.

Table 6: Overall parenting styles and self-efficacy correlation coefficients

\begin{tabular}{|l|l|l|l|l|}
\hline Model & $\mathrm{R}$ & $\mathrm{R}$ Square & Adjusted R Square & Std. Error of the Estimate \\
\hline 1 & $.377^{\mathrm{a}}$ & .142 & .142 & .70993 \\
\hline
\end{tabular}


Table 7: Anova table

\begin{tabular}{|l|l|l|l|l|l|l|}
\hline \multicolumn{2}{|l|}{ Model } & $\begin{array}{l}\text { Sum } \\
\text { Squares }\end{array}$ & of & $\begin{array}{l}\text { Mean } \\
\text { Square }\end{array}$ & F & Sig. \\
\hline 1 & Regression & 23.834 & 4 & 5.959 & 11.82 & $.000^{\mathrm{b}}$ \\
& Residual & 145.246 & 285 & .511 & & \\
\cline { 2 - 7 } & Total & 161.305 & 289 & & & \\
\hline
\end{tabular}

Table 8: Coefficients of parenting styles and self-efficacy

\begin{tabular}{|l|l|l|l|l|l|l|}
\hline \multicolumn{2}{|l|}{ Model } & \multicolumn{2}{|l|}{ Unstandardized Coefficients } & $\begin{array}{l}\text { Standardized } \\
\text { Coefficients }\end{array}$ & T & Sig. \\
\cline { 3 - 8 } \multicolumn{2}{|l}{} & B & Std. Error & Beta & & \\
\hline \multirow{1}{*}{1} & (Constant) & 1.789 & .337 & & 5.301 & .000 \\
\cline { 2 - 7 } & Authoritative & .369 & .065 & .341 & 5.673 & .000 \\
\cline { 2 - 7 } & Authoritarian & .050 & .064 & .045 & .775 & .439 \\
\cline { 2 - 7 } & Permissive & .108 & .070 & .089 & 1.556 & .121 \\
\cline { 2 - 7 } & Uninvolved & -.025 & .060 & -.024 & .416 & .678 \\
\hline \multicolumn{2}{|l|}{ a. Dependent Variable: Self-efficacy } \\
\hline
\end{tabular}

As presented in Table 6 the model summary above indicates that Adjusted R Square $=.142$; taken as a set, the predictors parenting styles (authoritative, authoritarian, permissive and uninvolved account for 14.2\% variation of self-efficacy among secondary school students in Ibanda North, Ibanda district. The overall model was statistically significant in explaining the relationship between parenting styles and self-efficacy among student's $\mathrm{F}(4)=11.822, \mathrm{p}(.000)<.05$.

The unstandardized coefficients presented in Table 8 indicated that for increase of 1 perception score in authoritative parenting style will increase students' self-efficacy of $0.369(36.9 \%)$ and this was found to be a significant change $t(285)=5.673, p(.000)<.05$. One-unit increase of perception of authoritarian parenting style will increase students' self-efficacy of .050 , but this was not found to be significant $t$ $(285)=.775, p(.439)>.05$. For permissive parenting style, it is indicated that its increase by one score will increase students' self-efficacy of 0.108 , which is not significant $(284)=1.1556,(.121)>.05$. Results further revealed that 1-unit increase of uninvolved parenting style will increase students' self-efficacy of -0.025 , which was also found not to be significant $t(284)=-416, p(.678)>.05$.

In the model, results indicated that in the presence of authoritative parenting style other explanatory variables of authoritarian, permissive and uninvolved parenting styles are not useful in predicting self- 
efficacy of secondary school students in Ibanda North, Ibanda District because they were not statistically significant in predicting self-efficacy.

\section{Discussion}

The main purpose of this study was to investigate the relationships between parenting styles and selfefficacy among secondary school students. According to the results of the conducted correlational analysis, authoritative and authoritarian parenting styles are vital in enhancing self-efficacy among secondary school students. This is because, positive significant relationships emerged between authoritative and authoritarian and self-efficacy. These findings are contrary with Nessai et al. (2015) who conducted a similar study among students of Islamic Azad University, Iran. In a similar sense, a significant correlation between authoritative parenting styles and self-efficacy is shown among students (Turner et al., 2009; Tam et al., 2012; Theresya et al., 2018). Tam et al. (2012) results confirmed that authoritative parenting styles contribute $12.8 \%$ of self-efficacy among students. Our current study denotes that authoritative parenting style contributes $36.9 \%$ of self-efficacy among secondary school students. This variation could be attributed to contextual and time factors between the two studies. Contrary to the current study, Tam et al. (2012) concluded that authoritarian parenting style had no significant relationship with self-efficacy.

On the other hand, permissive and uninvolved parenting did not contribute to self-efficacy among secondary school students. This is because the study results did not show any significant relationship between them and self-efficacy. The relationship between permissive parenting style and self-efficacy was positive $(r=0.088, p>0.01$ but not significant implying that the impact of permissive parenting style in supporting self-efficacy is minimal. Different from other parenting styles, results give a supporting proof that uninvolved parenting style is negatively related to students' self-efficacy. This implies uninvolved parenting style negatively affects self-efficacy among secondary school students in Ibanda North, Ibanda District. These results agree with earlier studies on parenting styles and self-efficacy (Olubunmi et al., 2019; Theresya et al., 2018; Turner et al., 2009; Qamar et al., 2017; Canter, 2009) However, this was not the case (Aldhafri, 2011) who found out that permissive parenting together with authoritative parenting style are effective in contributing to academic self-efficacy.

Generally, all parenting styles taken together indicated a positive relationship with self-efficacy $(\mathrm{r}=0$. $.620, \mathrm{p}>0.01)$. This provided sufficient evidence that parenting should be taken care of by all stakeholders in secondary schools for good contribution of self-efficacy which could subsequently lead to good academic performance. The pattern of the above findings is consistent with the previous literature (Mihret et al.,2019; Inam et al.,2016; Kashahu et al., 2014).

On establishing the contribution of each parenting style on predicting self-efficacy among secondary school students in Ibanda North, Ibanda District; our study results confirmed that it is only authoritative parenting style which is significant in predicting self-efficacy $t(285)=5.673, p(.000)<.05$. Unstandardized coefficients (see Table 8) indicated that for increase of 1 perception score in authoritative parenting style will increase students' self-efficacy of $0.369(36.9 \%)$.

In explaining the above results, it can be stated that authoritative parenting styles is the most effective parenting style in supporting students' self-efficacy and actually psychological wellbeing of students. With 
authoritative parenting style, students are given opportunity to discuss matters and decisions with their parents (Vafaeenejad et al., 2019; Walton et al., 2018; Alnafea \& Curtis, 2017; Masud et al., 2016; Kuppens \& Ceulemans, 2019; Hoang, 2007). This develops students autonomy, positive self-concept and belief (Kuppens \& Ceulemans, 2019). Children from authoritative parenting environment respect their self-worth, take themselves confident and possess high levels of self-belief (Seroussi \& Yaffe, 2020; Mihret et al., 2019; Odongo et al., 2016; Chukwumezie, 2010; Joussemet et al., 2008).

Although our regression model results showed that authoritarian parenting style does not significantly contribute to self-efficacy, guided by our correlation results that indicated a positive significant relationship with self-efficacy, it can be explained that its contribution on self-efficacy is also important. Learning to be responsible for ones decisions and actions emerges from authoritarian settings (Kemunto, 2016; Kashahu et al., 2014; Michel et al, 2004; Robinson et al., 1995). Therefore, authoritarian parenting style partially has a role to play in advancing self-efficacy among secondary school students.

Permissive parenting had no significant relationship with self-efficacy, the regression results also indicated that it was not important in predicting students' self-efficacy. It can hence be stated that it is not a desirable parenting style for children and students. Permissive parenting is associated with students' behaviors of low self-regard carelessness, laziness, fear to try attempting hard tasks, demotivation and at times deviant behavior (Manyama, 2017; Boothby et al., 2017; Nwosu et al., 2016; Nessai et al., 2015; Kashahu et al., 2014; Igbo \& Ihejiene, 2014)

Uninvolved parenting style is silent in early research and few studies that explored this parenting style had contradicting findings (Walton et al., 2018; Nessai et al., 2015) (Kemunto, 2016). Walton et al. (2018) indicate a positive relationship of neglectful parenting with self-efficacy dimensions of self-orientation which contradicted earlier findings that established that uninvolved/neglectful parenting style negatively related to self-efficacy dimensions (self-esteem, self-belief and self-regulation) including causing unpleasant children behaviors (Pinquart \& Gerke, 2019; Kemunto, 2016; Nwosu et al., 2016). Similar to the above studies, our study revealed that uninvolved parenting style is insignificantly negatively related to self-efficacy. This can be discussed that uninvolved parenting behaviors compromise students' selfesteem, self-belief and self-confidence in accomplishing tasks.

\section{Conclusions and Recommendations}

The moderate positive significant relationships authoritative and authoritarian parenting styles have with self-efficacy imply that if they are combined together, they can be of a great deal in enhancing students' self-efficacy. Deriving from the regression coefficient in table 8, it can be concluded that for holistic development of student's self, authoritative parenting should be practiced by parents in Ibanda, North, Ibanda district. Weak insignificant positive relationships permissive parenting style and self-efficacy and weak insignificant negative relationships between uninvolved parenting style and self-efficacy could bring down students' self-beliefs, self-realization, self-concept and self-confidence or hinder students' selfdevelopment which could eventually disadvantage their learning processes at school.

These lead to our recommendations that parents should adopt authoritative and authoritarian parenting styles, teachers should give necessary support to students taking in mind the parenting setting they could 
be coming from, schools should take an initiation of encouraging parents do adopt positive parenting styles. This might be achieved through arranging workshops for parents at school and having radio and television talk shows.

\section{References}

Aldhafri, S. (2011). Self-Efficacy and physical self-concept as mediators of parenting influence on adolescents' school and health wellbeing. Journal of Psychology in Africa 21(4), 511-520.

Alnafea, T., \& Curtis, D. D. (2017). Influence of mothers ' parenting styles on self-regulated academic learning among Saudi primary school students Self-regulated learning. Issues in Educational Research, 27(3).

Alsheikh, N. O. (2015). Parenting style, self-esteem and student performance in the united arab emirates. Current Issues in Education, 13(1).

Bandura, A. (2010). Self- efficacy. The Corsini encyclopedia of psychology, 1-3.

Baumrind, D., \& Black, A. E. (1967). Socialization practices associated with dimensions of competence in preschool boys and girls. Child Development, 291-327.

Boothby, N., Mugumya, F., Ritterbusch, A. E., Wanican, J., Ahabwe, C., Pizatella, A. D., Busi, S., \& Meyer, S. (2017). Child Abuse \& Neglect Ugandan households : A Study of parenting practices in three districts. Child Abuse \& Neglect, 67, 157-173. https://doi.org/10.1016/j.chiabu.2017.02.010

Cahyadi, S., \& Padjadjaran, U. (2018). Self-efficacy and self-regulated learning as predictors of students. The Open Psychology Journal, 2016, 9, 1-6 https://doi.org/10.2174/1874350101609010001

Canter, D. E. (2009). Self-appraisals, perfectionism, and academics in college undergraduates. Dissertation Abstracts International: Section B:\The Sciences and Engineering, 69(7-B), 4467. Retrieved on $22^{\text {nd }}$ March, 2021 from http://libproxy.sdsu.edu/login?url=http://search.ebscohost.com/login.aspx?direct=true\&db=ps yh\&AN=2009-99020-167\&site=ehost-live

Chukwumezie, M. (2010). Influence of family relationship , parenting style and self-esteem on delinquent behaviour among juveniles in remand homes. Global Journal of Human Social Science 10(2), 46-56.

Cornelius-Ukpepi, B., \& Ndifon, R. (2015). Home stress and academic performance of junior secondary school students in integrated science. Journal of Scientific Research and Reports, 4(6), 533542. https://doi.org/10.9734/jsrr/2015/10302

Harter, S. (2011). Self-Development during adolescence. Encyclopedia of Adolescence, 1(2), 307-315. https://doi.org/10.1016/B978-0-12-373951-3.00036-3

Hayat, A. A., Shateri, K., Amini, M., \& Shokrpour, N. (2020). Relationships between academic selfefficacy, learning-related emotions, and metacognitive learning strategies with academic performance in medical students: A structural equation model. BMC Medical Education, 20(1), 1-11. https://doi.org/10.1186/s12909-020-01995-9

Hoang, T. (2007). The relations between parenting and adolescent motivation. International Journal of Whole Schooling, 3(2), 1-21.

Huber, M., \& Melly, B. (2015). A test of the conditional independence assumption in sample selection models. Journal of Applied Econometrics, 30(7), 1144-1168. https://doi.org/10.1002/jae.2431

Igbo, J. N., \& Ihejiene, M. A. (2014). Influence of parenting styles on deviant behaviors and academic achievement of secondary school students in Garoua, Northern Cameroun. International Journal of Educational Science and Research, 4(5), 19-34. 
Inam, A., Nomaan, S., \& Abiodullah, M. (2016). Parents' parenting styles and academic achievement of underachievers and high achievers at middle school level. Bulletin of Education and Research, 38(1), 57-74.

Joshi, H. (2012). Multicollinearity diagnostics in statistical modeling and remedies to deal with it using SAS. Pharmaceutical Users Software Exchange, 1, 1-34.

Joussemet, M., Landry, R., \& Koestner, R. (2008). A self-determination theory perspective on parenting. Canadian Psychology, 49(3), 194-200. https://doi.org/10.1037/a0012754

Kashahu, L., Dibra, G., Osmanaga, F., \& Bushati, J. (2014). The relationship between parental demographics, parenting styles and student academic achievement. European Scientific Journal, 10(13), 2014.

https://www.academia.edu/27581672/The_Relationship_Between_Parental_Demographics_P arenting_Styles_and_Student_Academic_Achievement

Kemeza, I., Kibanja, M. G., \& Steffens, K. (2020). Assessment of self-efficacy beliefs and academic performance for sources and implications in high and low achieving secondary schools in Mbarara district, Uganda. 6(3), 1053-1057.

Kemunto, L. (2016). The influence of parenting styles on 1 earners ' involvement in behaviour disorders in Nairobi. International Journal of Science and Research 5(12), 1303-1314. https://doi.org/10.21275/ART20163688

Kuppens, S., \& Ceulemans, E. (2019). Parenting styles: A closer look at a well-known concept. Journal of Child and Family Studies, 28(1), 168-181. https://doi.org/10.1007/s10826-018-1242-x

Li, S., Peng, L., \& Tu, Y. (2020). A Unified Approach to Testing Independence in Econometric Models *. March. Accessed online on 22 ${ }^{\text {nd }}$, March 2021 from https://www.researchgate.net/publication/340224984_A_Unified_Approach_to_Testing_Inde pendence_in_Econometric_Models

Maccoby, E.E., \& Martin, J.A. (1983). Socialization in the context of the family: Parent-child interaction. In P. Mussen and E.M. Hetherington, editors, Handbook of Child Psychology, volume IV: Socialization, personality, and social development. New York: Wiley

Manyama, W. (2017). Which one is the best parenting style in early childhoods' psycho-social development in Tanzania? A Review of Literature. The International Journal of Humanities \& Social Studies 5(4), 176-183.

Masud, H., Ahmad, M. S., Jan, F. A., \& Jamil, A. (2016). Relationship between parenting styles and academic performance of adolescents: mediating role of self-efficacy. Asia Pacific Education Review, 17(1), 121-131. https://doi.org/10.1007/s12564-015-9413-6

Meera, K. P., \& Jumana, M. K. (2015). Self-Efficacy and academic performance in english. Research in Pedagogy, 5(2), 25-30. https://doi.org/10.17810/2015.13

Michelle M. Englund, M. M., Luckner, A. E., Whaley, G. J. L., \& Egeland, B. (2004). Effects of differences in parenting styles on. Journal of Educational Psychology, 4(96), 723-730.

Mihret, A. M., Dilgasa, G. S., \& Mamo, T. H. (2019). Parenting style as correlates of adolescents' academic achievement motivation of bate secondary school, Haramaya, Ethiopia. International Journal of Education and Literacy Studies, 7(2), 172. https://doi.org/10.7575/aiac.ijels.v.7n.2p.172

Mishra, P., Pandey, C. M., Singh, U., Gupta, A., Sahu, C., \& Keshri, A. (2019). Descriptive statistics and normality tests for statistical data. Annals of Cardiac Anaesthesia, 22(1), 67.

Nessai, V., Rastegar, D., Rajaei, A., \& Khoynejad, G. (2015). Comparing the Parenting styles and selfefficacy. Journal of Applied Environmental and Biological Sciences 5, 16-20.

Nwosu, K. C., Nwanguma, V. C., \& Onyebuchi, G. C. (2016). Parenting styles, test anxiety, and selfefficacy of secondary school students in Nigeria : Lessons from Nigerian sociocultural context. Educational Research Journal, 6(February), 32-41. 
Odongo, A. A., Aloka, P. J. O., \& Raburu, P. (2016). Influence of parenting styles on the adolescent students' academic achievement in Kenyan day secondary schools. Journal of Education and Practice, 7(15), 101-108.

Olubunmi, M. B., Oluyemi, I. S., \& Samuel, A. A. (2019). Parenting styles, sex education locality and self-efficacy as predictors of teenagers' experiment with sex. International Journal of Psychological Studies 11(2), 80-87. https://doi.org/10.5539/ijps.v11n2p80

Oyugi, J. L. (2015). The mediating effect of self-efficacy on the relationship between entrepreneurship education and entrepreneurial intentions of university students in Uganda. Journal of Entrepreneurship, Management and Innovation: https://doi.org/10.7341/20151122

Lord, E. S, Eccles, E. S., \& Karen, A., M. (1994). Surviving the junior high school transition family process and self perceptions as a protective and risk factors. The Journal of Early Adolescence, 14 (2).

Pinquart, M., \& Gerke, D. C. (2019). Associations of parenting styles with self-esteem in children and adolescents: A meta-analysis. Journal of Child and Family Studies, 28(8), 2017-2035. https://doi.org/10.1007/s10826-019-01417-5

Power, T. G. (2015). Parenting dimensions and styles: A brief history and recommendations for future research. August 2013. https://doi.org/10.1089/chi.2013.0034

Qamar, A., Parveen, Q., \& Yousuf, M. I. (2017). Relationship between Parenting Styles and Academic Self-efficacy of Students. The Anthropologist, 28(1-2), 123-129. https://doi.org/10.1080/09720073.2017.1316611

Raval, V. V., Ward, R. M., Raval, P. H., \& Trivedi, S. S. (2013). Confirmatory and exploratory factor analyses of Parental Authority Questionnaire in urban India. Journal of Child and Family Studies, 22(5), 707-718.

Robinson, C. C., Mandleco, B., Olsen, S. F., \& Hart, C. H. (1995). Authoritative, authoritarian, and permissive parenting practices: Development of a new measure. Psychological Reports, 77(3), 819-830. https://doi.org/10.2466/pr0.1995.77.3.819

Schwarzer, R., \& Jerusalem, M. (1995). Optimistic self-beliefs as a resource factor in coping with stress. In Extreme stress and communities: Impact and intervention (pp. 159-177). Springer, Dordrecht.

Senaviratna, N. A. M. R., \& A. Cooray, T. M. J. (2019). Diagnosing multicollinearity of logistic regression model. Asian Journal of Probability and Statistics, October, 1-9. https://doi.org/10.9734/ajpas/2019/v5i230132

Seroussi, D. E., \& Yaffe, Y. (2020). Links Between Israeli college students' self-regulated learning and their recollections of their parents' parenting styles. SAGE Open, 10(1). https://doi.org/10.1177/2158244019899096

Shkullaku, R. (2013). The relationship between self - efficacy and academic performance in the context of gender among Albanian students. European Academic Research, 1 (4), 467-478.

Tam, C., Chong, A., Kadirvelu, A., \& Khoo, Y. (2012). Parenting styles and self-efficacy of adolescents: Malaysian scenario. Global Jurnal of Human Social Science Arts \& Humanities, 12(14), 1925.

Theresya, J., Latifah, M., \& Hernawati, N. (2018). The effect of parenting style, self-efficacy, and self regulated learning on adolescents' academic achievement. Journal of Child Development Studies, 3(1), 28. https://doi.org/10.29244/jcds.3.1.28-43

Turner, E. A., Chandler, M., \& Heffer, R. W. (2009). The influence of parenting styles, achievement motivation, and self-efficacy on academic performance in college students. Journal of College Student Development, 50(3), 337-346. https://doi.org/10.1353/csd.0.0073

Turner, E. A., Heffer, R. W., Turner, E. A., Chandler, M., \& Heffer, R. W. (2009). The influence of parenting styles, achievement motivation, and self-efficacy on academic performance in college students the influence of parenting styles , achievement motivation , and self-efficacy 
on academic performance in college students. Journal of College Student Development 50(3), 337-346.

Ullah, M. I., Aslam, M., Altaf, S., \& Ahmed, M. (2019). Some new diagnostics of multicollinearity in linear regression model. Sains Malaysiana, 48(9), 2051-2060. https://doi.org/10.17576/jsm2019-4809-26.

Vafaeenejad, Z., Elyasi, F., \& Moosazadeh, M. (2019). Psychological factors contributing to parenting styles: A systematic review [version 2; peer review : 1 approved, 1 not approved ]. 1-19.

Walton, G. E., Hibbard, D. R., Coughlin, C., Coyl-shepherd, D. D., \& Walton, G. E. (2018). Parenting, personality, and culture as predictors of perfectionism. Current Psychology, 39, 681-693. 